\title{
Study of Poisoning Cases in a Tertiary Care Hospital
}

\author{
Karki RK, ${ }^{1}$ Risal $A^{2}$
}

${ }^{1}$ Department of Forensic Medicine and Toxicology

${ }^{2}$ Department of Psychiatry

Kathamndu University School of Medical Sciences

Dhulikhel Hospital, Kavre, Nepal

\section{Corresponding author}

Raj Kumar Karki

Department of Forensic Medicine and Toxicology

Kathamndu University School of Medical Sciences

Dhulikhel Hospital, Kavre, Nepal

Email: rkkarki17@hotmail.com

\section{Citation}

Karki RK, Risal A. Study of Poisoning Cases in a Tertiary Care Hospital. Kathmandu Univ Med J 2012;10(4):7073.

\begin{abstract}
Background

Poisoning is one of the leading causes of morbidity and mortality in Nepal and also a major public health problem worldwide. A thorough review of the risk factors helps to decrease the incidence and mortality. The study evaluates the cases admitted in Dhulikhel Hospital, Kavre, Various parameters like age, sex, marital status, time of ingestion, month of occurrence, agent responsible for incidence; type of poisoning, psychosocial problem, outcome and duration of treatment are analyzed.
\end{abstract}

\section{Objectives}

The objectives of this study are to determine the pattern and severity of poisoning cases admitted to Dhulikhel Hospital.

\section{Methods}

A hospital based study was carried out in the patient admitted to Dhulikhel Hospital with the history of poisoning for the period of one year between April 2011 to March 2012. Various parameters were analyzed and compared with other study.

\section{Results}

There were 137 cases during the one year duration and maximum case belonged to second and third decade of life. Most common manner of poisoning was suicidal and the incidence was mainly during evening hours. Organophosphorus was the most commonly abused substance. Most of the cases had arrived hospital after one hour of exposure and duration of hospital stay in many cases were less than four days.

\section{Conclusion}

Based on these findings preventive measures like precaution taken at various levels, restriction in free sale of the poisons and promoting Poison Information Centers along with public awareness and proper psychosocial management to decrease the incidence and mortality in poisoning cases can be suggested.

\section{KEY WORDS}

Poisoning, morbidity, mortality

\section{INTRODUCTION}

Poison is a substance capable of producing damage or dysfunction in the body by its chemical activity. It can enter the body in various ways to produce general or local effects. Since the origin of the mankind in this world, poisoning always remained associated with it, though it was mostly accidental in nature in the earlier times. ${ }^{1}$ Poisons are subtle and silent weapons, which can be easily used without violence and often without arousing suspicion. ${ }^{2}$ Poisoning is a medical emergency and a patient is always invariably rushed to the hospital at the earliest possible moment, irrespective of the amount and nature of poison ingested. All the cases of poisoning are admitted through emergency services where the safety of life of the patient is the main issue for the doctor. ${ }^{3}$ Uncontrolled use of poisons in the developing countries has resulted in increased number of human fatalities year by year. The nature of poison varies in different parts of the world and may vary even in different parts of the same country depending upon the socioeconomic factors and cultural diversity.

Over the last few decades, agricultural pesticides have become common household items in the developing world, which are commonly used for self poisoning. ${ }^{2}$ Whether intentional or accidental, it is the easy access to these substances that significantly adds to the incidence. In Nepal, Narcotic Drug Control Act, 2038 and Pesticide Act 2048, prohibits the misuse of narcotics and pesticides. However improper implementation of these has lead to such problems. ${ }^{4}$ We aimed to study poisoning cases admitted in a tertiary care hospital and suggest preventive measures to bring down incidence and there by mortality. 


\section{METHODS}

This is a prospective study in which all the acute poisoning cases admitted in Dhulikhel Hospital, Kavre, during the period of April 2011 to March 2012 were studied. A total of 137 such cases attended during this period and all cases were received in the casualty and later admitted in the wards. Epidemiological factors like age, sex, occupation, marital status, religion and person who brought the patient to hospital were studied. Chronological factors like time of consumption, time elapse in presentation to hospital, seasonal incidence and duration of hospital stay were studied. Types of poison consumed, manner and mortality ratio were also studied. The collected data were analyzed by Microsoft Excel 2010 software using simple manual analysis of frequency and percentage.

\section{RESULTS}

The study sample included 75 males (54.7\%) and 62 females (45.3\%). The maximum number of cases were seen during the third decade (32.1\%) followed by fourth decade (22.6\%). Majority of them were unemployed $(42.4 \%)$ followed by farmers (29.2\%) and married (63.5\%) belonging to rural areas. More than two third (72.2\%) belonged to low socio-economic status of the society. The incidence of poisoning was higher in the rainy season. All the victims had consumed poison orally. In 38 cases, alcohol was taken along with poison. Pesticides were the most common poisons $(78.1 \%)$ consumed mainly during evening hours. Most of them consumed knowingly (78.1\%) followed by accidental (21.1\%). Many of the cases arrived to hospital after more than one hour of consumption (76.7\%) and in hired vehicle (61.3\%). Most of the cases were non fatal and were discharged from hospital within four days (62.1\%).

\section{DISCUSSION}

Poisoning is one of the leading causes of morbidity and mortality in Nepal and also a major public health problem worldwide. The World Health Organization(WHO) estimated that there were 873,000 suicides worldwide in 2002 which make suicide a majour cause of premature mortality globally. ${ }^{5}$ The WHO reports that pesticides are now the most common method of suicide worldwide. ${ }^{6}$ In Nepal, the development of applied chemistry in industry, agriculture and household use has been more rapid than the development of child safety, worker protection and environmental health concerns. ${ }^{7}$ Acute poisoning is an important clinical emergency and early diagnosis, treatment and prevention are crucial in reducing the burden of poisoning related injury in any country. ${ }^{8} \mathrm{~A}$ thorough review of the risk factors helps to decrease the incidence and mortality.

In spite of advanced medical treatment and awareness, the fatal outcome from exposure (inhalation, skin contacts and ingestion) to the chemicals of agricultural and domestic use
Table. 1 Socio-demographic findings.

\begin{tabular}{|c|c|c|}
\hline \multicolumn{3}{|c|}{ Age group (years) } \\
\hline & No. of cases & Percentage \\
\hline $0-10$ & 07 & 05.1 \\
\hline $11-20$ & 28 & 20.5 \\
\hline $21-30$ & 44 & 32.1 \\
\hline $31-40$ & 31 & 22.6 \\
\hline $41-50$ & 20 & 14.6 \\
\hline$>50$ & 07 & 05.1 \\
\hline \multicolumn{3}{|c|}{ Sex } \\
\hline & No. of cases & Percentage \\
\hline Male & 75 & 54.7 \\
\hline Female & 62 & 45.3 \\
\hline \multicolumn{3}{|c|}{ Caste } \\
\hline & No of cases & Percentage \\
\hline Tamang/Lama & 49 & 33.6 \\
\hline Brahmin & 29 & 21.2 \\
\hline Chettri & 26 & 18.9 \\
\hline Newar & 26 & 16.2 \\
\hline Others & 14 & 10.1 \\
\hline \multicolumn{3}{|c|}{ Occupation } \\
\hline & No. of cases & Percentage \\
\hline Unemployed & 58 & 42.4 \\
\hline Farmer & 40 & 29.2 \\
\hline Student & 25 & 18.3 \\
\hline Other & 14 & 10.1 \\
\hline \multicolumn{3}{|c|}{ Marital status } \\
\hline & No of cases & Percentage \\
\hline Married & 87 & 63.5 \\
\hline Unmarried & 38 & 27.7 \\
\hline Divorce & 07 & 05.1 \\
\hline Widow & 05 & 03.7 \\
\hline \multicolumn{3}{|c|}{ Socioeconomic status } \\
\hline & No of cases & Percentage \\
\hline Low & 99 & 72.2 \\
\hline Middle & 33 & 24.1 \\
\hline High & 05 & 03.7 \\
\hline
\end{tabular}

is increasing day by day. Easy availability, extensive use and low cost of the chemicals, all make the population more vulnerable for accidental as well as suicidal poisoning. The incidences are increasing day by day. Hospital based studies from five majour hospitals in Nepal in $1990-2000$ showed that organophosphorus compounds were the most common form of poisoning comprising $52 \%$ of total cases. ${ }^{9}$ A study showed an increase from 3.2\% in year 2045-2048 BS to $4.2 \%$ in year 2055-2058 BS in Patan Hospital, Nepal. ${ }^{4}$ Another report shows that incidence of acute poisoning increased by $19.23 \%$ in one year $1997-1998$ and by 3.86 $\%$ from January 1999 to June $2001 .{ }^{10}$ A steady increase in the number of percentage of poisoning cases admitted in Tribhuwan University Teaching Hospital, Kathmandu, was seen, from $0.1 \%$ to $0.5 \%$ during year $1986-1992 .{ }^{11}$ Similar 


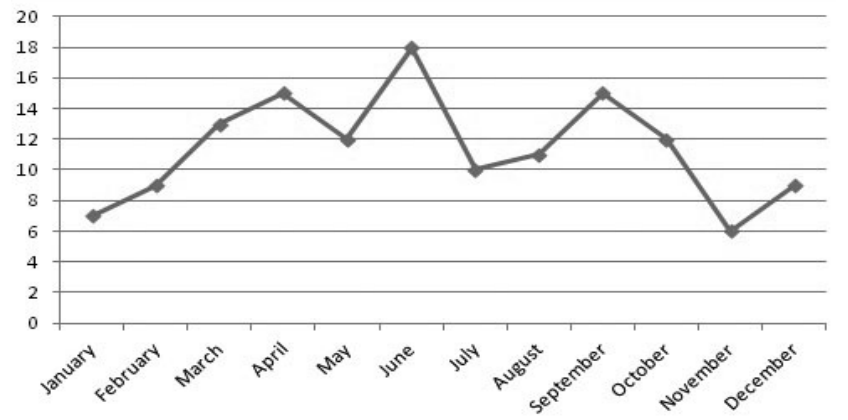

Figure 1. Month wise case presentation.

Table. 2 Chronological findings.

\begin{tabular}{|c|c|c|}
\hline \multicolumn{3}{|c|}{ Time of incidence } \\
\hline & No. of cases & Percentage \\
\hline 00:00-06:00 & 08 & 05.8 \\
\hline 06:01-12:00 & 28 & 20.5 \\
\hline 12:01-18:00 & 51 & 36.5 \\
\hline $18: 01-24: 00$ & 50 & 37.2 \\
\hline \multicolumn{3}{|c|}{ Time of Hospital arrival } \\
\hline & No. of cases & Percentage \\
\hline Within one hour & 32 & 23.3 \\
\hline After one hour & 105 & 76.7 \\
\hline \multicolumn{3}{|c|}{ Brought by } \\
\hline & No. of cases & Percentage \\
\hline Relatives & 106 & 77.4 \\
\hline Neighbour & 17 & 12.4 \\
\hline Friends & 08 & 05.8 \\
\hline Police & 06 & 04.4 \\
\hline \multicolumn{3}{|c|}{ Referred case } \\
\hline & No. of cases & Percentage \\
\hline Yes & 35 & 25.5 \\
\hline No & 102 & 74.5 \\
\hline \multicolumn{3}{|c|}{ Duration of hospital stay and mortality } \\
\hline & No. of cases & Percentage \\
\hline $1-4$ days & 85 & 62.1 \\
\hline $5-7$ days & 25 & 20.5 \\
\hline$>7$ days & 18 & 13.1 \\
\hline Expired & 04 & 02.9 \\
\hline Brought dead & 02 & 01.4 \\
\hline
\end{tabular}

results were observed in the studies in Bir Hospital. ${ }^{11}$ In Nepal, the most common poisons are organophosphates however it is gradually overcome by the use of Phosphides and similar rodenticides, due to their fast and more effective action. ${ }^{12-14}$

In the present study, higher incidence in the third decade could be due to an increased stress exerted on an individual with exposure to different social, economical, domestic and occupational pressures. In the second decade, pressure may be due to immature thoughts, competition in education, early marriages and inability to cope with the post marital pressures especially in rural areas. There is no much variation between males and females in the
Table. 3 Trends of poisoning.

\begin{tabular}{|c|c|c|}
\hline \multicolumn{3}{|c|}{ Manner } \\
\hline & No. of cases & Percentage \\
\hline Suicidal & 107 & 78.1 \\
\hline Accidental & 29 & 21.1 \\
\hline \multirow[t]{3}{*}{ Homicidal } & 01 & 00.8 \\
\hline & \multicolumn{2}{|c|}{ Consumed with alcohol } \\
\hline & No of cases & Percentage \\
\hline Yes & 38 & 27.7 \\
\hline No & 99 & 72.3 \\
\hline \multicolumn{3}{|c|}{ Type of poison } \\
\hline & No of cases & Percentage \\
\hline Organ phosphorus & 56 & 40.9 \\
\hline $\begin{array}{l}\text { Almunium Phos- } \\
\text { phide }\end{array}$ & 17 & 12.4 \\
\hline Metacid/Novan & 18 & 13.1 \\
\hline Corrosive & 04 & 02.9 \\
\hline Kerosene & 07 & 05.1 \\
\hline Dhatura & 06 & 04.4 \\
\hline Alcohol & 08 & 05.8 \\
\hline Benzodiazepam & 06 & 04.4 \\
\hline Mushroom & 02 & 01.4 \\
\hline Unknown & 13 & 09.6 \\
\hline
\end{tabular}

incidence of poisoning. Most of the victims in our study are the unemployed and farmers from low socio- economic status living in rural areas. This could be due to the reason of agriculture being the dominant profession in our country. Easy availability of pesticides and consumption mainly during evening hours could be explained as people usually meet in homes after working hours and discuss about their problems and get frustrated that result in taking the extreme step. The increased incidence in rainy season could be due to increase availability of pesticides and frustration resulting from the loss of crops as a result of excessive or inadequate rain. Majority of victims in the present study committed suicide, which could be due to the highly variable income to lead a day-to-day life by the rural people especially the farmers who come across various stressful situations in their life. Depression is one of the commonest psychiatric diagnoses related to suicide. ${ }^{15}$ Alcohol present as an associated inebriant in 38 cases may explain the fear of death in these people. In the present study pesticides were the main choice by the victims, which explains that suiciders commonly choose household poisons which are easily available in rural areas.

\section{CONCLUSION}

In the present study, most of the victims were married rural agricultural workers belonging to low socio-economic status. Most of them consumed during evening hours with a suicidal intention and agricultural poisons were commonly used. Patient with intentional poisoning must undergo psychiatry consultation during their stay in the hospital which will minimize the risk of next attempt of 
self harm. Strict rules must be followed regarding sale of pesticides.

\section{REFERENCES}

1. Gorea RK, Dalal JS, Gargi J, Rai H. Pattern of Poisoning in Punjab. J Punjab Acad Forensic Med Toxicol 2001; 1: 6-8.

2. Pothireddy S, Mohanty MK. Study of poisoning cases in a tertiary care Hospital. JSIMLA 2011; 3: 14-18.

3. Dash SK, Raju As, Mohanty MK, Patnaika KK, Siddhartha P, Mohanty S. Socioeconomic Profiles of Poisoning Cases. JIAFM 2005; 27: 133-138.

4. Pokhrel D, Pant S, Pradhan A, Mansoor S. A comparative study of Poisoning cases in Central, Zonal and District Hospitals. KUJSET 2008; 5: $40-48$

5. World Health Report 2004. WHO, Geneva; 2004.

6. Bertolote JM, Fleischmann A, Butchart A, Besbelli N. Suicide attempts and Pesticides: a major hidden problem.Bull World Health Organ 2006, 84: 260.

7. Lohani SP. An epidemiological Study of Poisoning cases Reported to the Nepal Drug and Poison Information Center, Kathmandu. Nepal Drug and Poison Center.

8. Marahatta SB, Singh J, Shrestha R, Koju R. Poisoning cases attending Emergency department in Dhulikhel Hospital - Kathmandu University Teaching Hospital. KUMJ 2009; 2: 152-156.

\section{ACKNOWLEDGEMENT}

Our sincere thanks to Seshananda Sanjel, Department of Community Medicine, KUSMS
9. Gupta SK, Joshi MP. Pesticide Poisoning Cases Attending Five Major Hospitals of Nepal. J Nep Med Assoc 2002; 41: 447-456.

10. Bharati U, Shrestha JB, Sharma M. Study of Acute Poisoning in Nepal Medical College Teaching Hospital. NMCJ 2001; 2: 83.

11. Kafle KK, Gyawali KK. Organophosphorous Most common poisoning Agent. J Inst Med 1992; 14: 228-233.

12. Pokhrel N, Gurung CK. A study of poisoning case recorded in Bir Hospital over four years. J Inst Med 1987; 24-29.

13. Kar SM, Timilsinha S, Agrawal. An Epidemiological study of Organophosphorus Poisoning at Manipal Teaching Hospital, Pokhara, Nepal. JIAFM 2010; 32(2): 108-109.

14. Khadka SB, Ale SB. A study of poisoning cases in emergency Kathmandu Medical College Teaching Hospital. KUMJ 2005; 3: 388391.

15. Risal A, Sharma PP. Psychiatric manifestations of patients admitted for intentional self harm. J Inst Med 2011; 33(1): 43-48. 